\title{
Evaluating the effects of different doses of ursodeoxycholic acid on neonatal jaundice
}

\author{
Manizheh Mostafa Gharehbaghi ${ }^{1 \oplus}$, Afsaneh Mokhallegh Sani ${ }^{2 \oplus}$, Mandana Refeey ${ }^{3 \oplus}$ \\ ${ }^{1}$ Woman's Reproductive Health Research Center, ${ }^{2}$ Department of Pediatrics and ${ }^{3}$ Liver and Gastrointestinal Diseases Research Center, \\ Tabriz University of Medical Sciences, Tabriz, Iran.
}

\begin{abstract}
Background. Icterus tends to be one of the most prevalent causes of neonatal hospitalization. The present study aimed to evaluate the effects of the different doses of ursodeoxycholic acid (UDCA) on neonatal jaundice.

Method. In this study, 120 newborns who were hospitalized for phototherapy were randomly assigned. Group A received phototherapy and UDCA $5 \mathrm{mg} / \mathrm{kg} /$ dose every 12 hours orally, group B patients were treated with phototherapy and UDCA $7.5 \mathrm{mg} / \mathrm{kg} /$ dose every 12 hours orally. Group C received phototherapy with a placebo. All patients were evaluated for bilirubin levels, the duration of phototherapy, and the length of hospital stay.

Results. The mean bilirubin level at hospital admission was $19.88 \pm 2.33 \mathrm{mg} / \mathrm{dl}$ in group A, $19.33 \pm 2.51 \mathrm{mg} /$ $\mathrm{dl}$ in group $\mathrm{B}$, and $19.76 \pm 2.64 \mathrm{mg} / \mathrm{dl}$ in group $\mathrm{C}(\mathrm{p}=0.58)$. The groups receiving phototherapy with UDCA showed a significant decrease in the bilirubin level. Bilirubin level decreased to $10.04 \pm 1.11 \mathrm{mg} / \mathrm{dl}$ in group A, $8.82 \pm 1.11 \mathrm{mg} / \mathrm{dl}$ in group $\mathrm{B}$, and $12.04 \pm 2.05 \mathrm{mg} / \mathrm{dl}$ in group $\mathrm{C}(\mathrm{p}=0.000)$. Furthermore, the mean duration of phototherapy, as well as the average length of hospital stay, were significantly lower in group B as compared to the other groups $(\mathrm{p}=0.000)$.

Conclusion. The findings of this study indicated that the administration of UDCA in addition to phototherapy could effectively decrease the length of hospital stay and bilirubin levels in neonatal hyperbilirubinemia. However, further studies with a larger sample size are required before one can recommend the routine use of UDCA for the treatment of neonatal jaundice.
\end{abstract}

Key words: bilirubin, hospital stay, neonatal jaundice, ursobil, ursodeoxycholic acid.

Hyperbilirubinemia tends to be one of the most prevalent health issues in neonates. Its prevalence has been reported in half of the term and the majority of the preterm neonates. ${ }^{1}$ Phototherapy is usually the mainstay for the treatment of indirect (unconjugated) hyperbilirubinemia. It reduces the plasma levels of unconjugated bilirubin, preventing kernicterus and decreasing the need for exchange transfusion. ${ }^{2}$ However, the use of this method is accompanied by several short or long term side effects. the short-term effects include interference in the maternal-infant relationship, dehydration, diarrhea, maculopapular rash,

$\triangle$ Mandana Refeey

mrafeey@yahoo.com

Received 2nd August 2019, revised 26th September 2019, accepted 12th November 2019. patent ductus arteriosus, and high hospital costs. $^{2-4}$ Several studies have been published to correlate phototherapy with the long-term side effects such as neoplasm, nevi, café au lait spots, and allergic diseases such as asthma, rhinitis, conjunctivitis, and the immune and inflammatory response. ${ }^{2}$

So far, various medications such as activated charcoal, d-penicillamine, phenobarbital, metalloporphyrin, clofibrate, and bile salts have been used for the treatment of indirect hyperbilirubinemia.5-8 The use of phenobarbital has been observed to reduce indirect hyperbilirubinemia and the duration of phototherapy; while, phenobarbital was shown to lead to some side effects in patients such as drowsiness, reduced rate of breastfeeding, and neurological disorders. ${ }^{8}$ 
Recently, ursodeoxycholic acid (UDCA) has been proposed to be used in the treatment of neonatal jaundice. Dietary bile salt administration induces a large, persistent decrease in plasma unconjugated bilirubin (UCB) concentrations in Gunn rats. ${ }^{9}$ UDCA enhances UCB turnover by increasing its fecal disposal. These results support the application of oral bile salt treatment in patients with unconjugated hyperbilirubinemia. ${ }^{9}$ It has already been widely used in the treatment of cholestatic hepatic diseases, gallstones, and primary biliary cholangitis and has resulted in a decrease in indirect bilirubin levels and the severity of jaundice. ${ }^{10}$ UDCA has been reported to play its role through anti-inflammatory, antiapoptosis, and immunomodulatory effects. It might also control the changes in bile acid levels. Besides, UDCA increases the secretion of bile acids from the liver, improves cell signaling, and preserves the integrity of mitochondria. ${ }^{10}$

Some studies have already evaluated the effects and dosing of UDCA in neonatal hyperbilirubinemia. For instance, Honar et al. ${ }^{11}$ suggested that using UDCA $(10 \mathrm{mg} / \mathrm{kg})$ along with phototherapy leads to a significant decrease in the indirect bilirubin level in neonatal jaundice. However, the information regarding its exact dosing in the treatment of neonatal jaundice is lacking. ${ }^{12-15}$ Considering the side effects of phototherapy ${ }^{2}$ and the effectiveness of UDCA on neonatal jaundice, this study was conducted to evaluate the effects of different doses of UDCA on decreasing neonatal hyperbilirubinemia and their length of hospital stay.

\section{Material and Methods}

The present study is a clinical trial, trying to evaluate the effects of UDCA in patients who were hospitalized with neonatal jaundice in the Pediatric Hospital of Tabriz, Iran, from January to December 2017. The inclusion criteria were having a birth weight of higher than $2500 \mathrm{~g}$, gestational age of over 35 weeks, total bilirubin level of $14-25 \mathrm{mg} / \mathrm{dl}$, and a direct bilirubin level of lower than $2 \mathrm{mg} / \mathrm{dl}$. The policy for treatment of neonatal hyperbilirubinemia in our center is based on AAP guidelines. ${ }^{3}$ The neonates who had $\mathrm{Rh}$ or $\mathrm{ABO}$ incompatibility (with positive direct coombs test), G6PD deficiency, direct hyperbilirubinemia, sepsis, Crigler-Najjar syndrome, thyroid disorders, hepatic diseases, and diabetic mothers were excluded from the study. We exclude G6PD deficiency, and thyroid disorders by routine lab tests. CriglerNajjar Syndrome was ruled out by unresponsive hyperbilirubinemia to phototherapy in follow up.

This study was approved by the Ethics Committee for Clinical Trials of Tabriz University of Medical Sciences and was registered in IRCT with the registration code of IRCT201701313915N18. Informed written consent was obtained from parents.

All of the neonates who had inclusion criteria and admitted only for the treatment of indirect hyperbilirubinemia were enrolled in this study based on AAP recommendations. The included neonates were randomly allocated into three groups, each consisting of 40 neonates. The patients were assigned to the groups randomly using a random number table. The patients in group A received intensive phototherapy (LED lamps) and UDCA was administered 10 $\mathrm{mg} / \mathrm{kg}$ in two divided doses (5 mg/kg/dose). Those in group B received phototherapy along with $15 \mathrm{mg} / \mathrm{kg}$ of UDCA in two divided doses (7.5 mg/kg/dose). Group C was the control group and the patients received phototherapy and the placebo. The termination criteria for phototherapy were decrease in total bilirubin concentration less than 50\% exchange threshold or bilirubin less than $10 \mathrm{mg} / \mathrm{dl}$. Throughout the study, the responsible physicians were kept blind to the grouping of the patients. Total and indirect bilirubin levels were measured by 1-1.5 $\mathrm{ml}$ blood at the $6,12,24$, and 48 hours after the admission and phototherapy. Changes in the bowel habits (i.e., diarrhea or constipation), and other complications such as vomiting, food intolerance, and nutritional disorders were compared in three groups. In this study, the 
primary outcome was the reduction of bilirubin level, and the secondary outcome was the length of stay in the hospital and the duration of phototherapy.

The demographic characteristics of the infants as well as bilirubin levels were recorded in a checklist. The gathered data were then fed into SPSS Software, Version 16 and the statistical analyses were performed by ANOVA and Chisquare tests. A p-value of less than 0.05 was considered significant in this study.

\section{Results}

This study was conducted on 120 neonates suffering from neonatal jaundice. The patients were allocated in 3 groups: group A (receiving phototherapy and UDCA $5 \mathrm{mg} / \mathrm{kg} /$ dose every 12 hours orally), group B (receiving phototherapy and UDCA $7.5 \mathrm{mg} / \mathrm{kg} /$ dose every 12 hours orally), and group $\mathrm{C}$ (just receiving phototherapy and placebo). Twenty-two patients $(55 \%)$ in group A, 24 patients $(60 \%)$ in group $\mathrm{B}$, and 22 patients $(55 \%)$ in group $\mathrm{C}$ were boys, and the rest were girls $(p=0.66)$. The three groups were not significantly different regarding the mean age $(p=0.26)$, gestational age at the time of delivery $(\mathrm{p}=0.49)$, and body weight at the time of admission $(p=0.66)$ and discharge from the hospital $(p=0.06)$. However, the weight gain during hospitalization was observed to be significantly higher in the control group as compared to the other groups $(\mathrm{p}=0.001)$ (Table I).

The direct bilirubin level was found to be lower than $2 \mathrm{mg} / \mathrm{dl}$ in all of the neonates. The indirect bilirubin level was also monitored at the time of admission and discharge from the hospital, as well as 6, 12, 24, and 48 hours after hospitalization. The results showed significant differences among the three groups, six hours after hospitalization. The bilirubin levels in groups A and B were significantly lower than that of the patients in group $\mathrm{C}$, at 6 hours after hospitalization (Table II). The comparison of bilirubin levels revealed that the patients receiving UDCA had lower levels as compared to the patients in the control group, at all measured times, except for upon the admission (Fig. 1).

Table I. General findings of the study groups.

\begin{tabular}{lcccc}
\hline & 5-mg group (A) & $7.5-\mathrm{mg}$ group (B) & Control (C) & p-value \\
& $\mathrm{N}=40$ & $\mathrm{~N}=40$ & $\mathrm{~N}=40$ & \\
\hline Age (days) & $5.91 \pm 2.49$ & $5.1 \pm 2.47$ & $5.91 \pm 2.49$ & 0.26 \\
Gestational age (weeks) & $37.75 \pm 4.93$ & $38.1 \pm 1.05$ & $38.55 \pm 1.01$ & 0.49 \\
Admission weight (gr) & $3175.41 \pm 561.53$ & $2961.71 \pm 440.03$ & $3192.91 \pm 431.02$ & 0.08 \\
Discharge weight (gr) & $3200.69 \pm 557.59$ & $3008.29 \pm 445.03$ & $3269.17 \pm 708.38$ & 0.06 \\
Weight changes during admission (gr) & 25.27 & 42.46 & 76.36 & 0.00 \\
\hline
\end{tabular}

Table II. Average bilirubin levels in study groups at different times.

\begin{tabular}{lcccc}
\hline & 5-mg group (A) & 7.5-mg group (B) & Control (C) & p-value \\
& $\mathrm{N}=40$ & $\mathrm{~N}=40$ & $\mathrm{~N}=40$ & \\
\hline Indirect bilirubin at admission $(\mathrm{mg} / \mathrm{dl})$ & $19.88 \pm 2.33$ & $19.33 \pm 2.51$ & $19.76 \pm 2.64$ & 0.58 \\
Direct bilirubin at admission $(\mathrm{mg} / \mathrm{dl})$ & $0.51 \pm 0.11$ & $0.91 \pm 0.42$ & $0.48 \pm 0.12$ & 0.39 \\
Indirect bilirubin at 6th hour(mg/dl) & $16.82 \pm 2.0$ & $15.78 \pm 2.44$ & $17.2 \pm 2.51$ & 0.01 \\
Indirect bilirubin at 12th hour(mg/dl) & $13.24 \pm 2.16$ & $12.07 \pm 2.15$ & $14.66 \pm 2.55$ & 0.000 \\
Indirect bilirubin at 24th hour(mg/dl) & $10.04 \pm 1.11$ & $8.82 \pm 1.11$ & $12.04 \pm 2.05$ & 0.000 \\
Indirect bilirubin at 48th hour(mg/dl) & $7.96 \pm 1.75$ & $6.21 \pm 1.06$ & $10.17 \pm 1.96$ & 0.000 \\
Indirect bilirubin at discharge $(\mathrm{mg} / \mathrm{dl})$ & $4.75 \pm 1.07$ & $4.74 \pm 0.63$ & $7.88 \pm 2.11$ & 0.000 \\
\hline
\end{tabular}




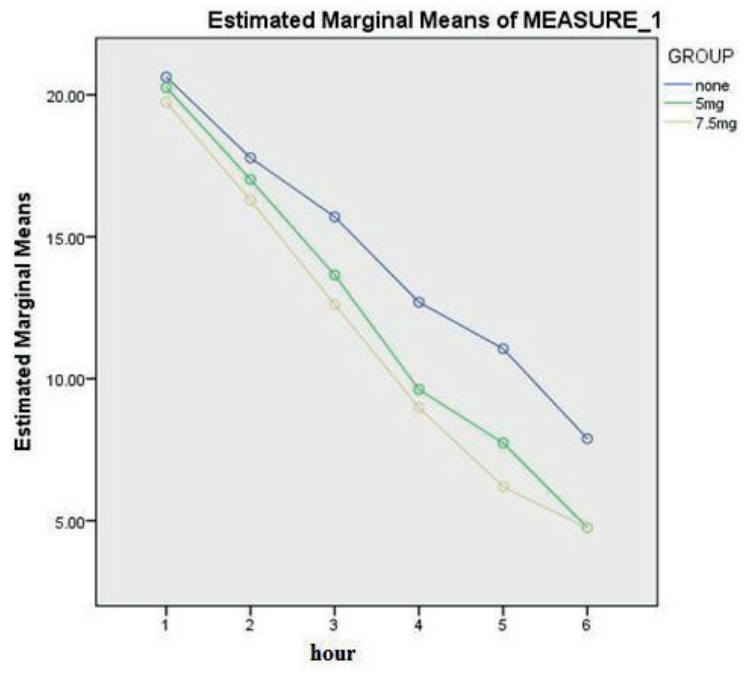

Fig. 1. The bilirubin levels in the three groups.

Furthermore, among the two groups receiving UDCA, the reduction of bilirubin was higher in the group of patients for whom the higher doses of medication were administered (Table III). The mean length of hospital stay was 29.47 \pm 16.80 hours for the patients in group A, $21.35 \pm$ 8.12 hours for the patients in group $B$, and 45.97 \pm 18.01 hours for the patients in group $\mathrm{C}(\mathrm{p}=$ 0.000 ). In all studied patients, the predominant source of nutrition was breast milk $(p=0.43)$ (Table IV). There were no cases of vomiting, food intolerance, or constipation in studied patients. Diarrhea was not seen in patients who received Ursobil significantly more than the placebo group.

\section{Discussion}

Ursodeoxycholic acid (UDCA) is widely used in the treatment of chronic cholestatic liver diseases. Recently, some studies have attempted to investigate the effect of this medication on infants with indirect hyperbilirubinemia. Based on the results of the present study higher doses of UDCA are more effective in decreasing the indirect bilirubin levels.

In a study conducted by Honar et al. ${ }^{11}$ the total bilirubin level of the infants 12, 24, and 48 hours after hospitalization was reported to be 12,10 , and $9.8 \mathrm{mg} / \mathrm{dl}$ in the UDCA group and

Table III. Comparison of indirect bilirubin levels in different groups.

\begin{tabular}{|c|c|c|c|c|}
\hline & $\begin{array}{l}\text { 5-mg group (A) } \\
\qquad \mathrm{N}=40\end{array}$ & $\begin{array}{l}\text { 7.5-mg group (B) } \\
\qquad \mathrm{N}=40\end{array}$ & $\begin{array}{l}\text { Control (C) } \\
\qquad \mathrm{N}=40\end{array}$ & p-value \\
\hline \multirow[t]{3}{*}{ Indirect bilirubin at admission $(\mathrm{mg} / \mathrm{dl})$} & $19.88 \pm 2.33$ & - & $19.76 \pm 2.64$ & 0.83 \\
\hline & - & $19.33 \pm 2.51$ & $19.76 \pm 2.64$ & 0.45 \\
\hline & $19.88 \pm 2.33$ & $19.33 \pm 2.51$ & - & 0.30 \\
\hline \multirow[t]{3}{*}{ Indirect bilirubin at 6 th hour(mg/dl) } & $16.82 \pm 2.0$ & - & $17.2 \pm 2.51$ & 0.89 \\
\hline & - & $15.78 \pm 2.44$ & $17.2 \pm 2.51$ & 0.04 \\
\hline & $16.82 \pm 2.0$ & $15.78 \pm 2.44$ & - & 0.04 \\
\hline \multirow[t]{3}{*}{ Indirect bilirubin at 12th hour(mg/dl) } & $13.24 \pm 2.16$ & - & $14.66 \pm 2.55$ & 0.009 \\
\hline & - & $12.07 \pm 2.15$ & $14.66 \pm 2.55$ & 0.000 \\
\hline & $13.24 \pm 2.16$ & $12.07 \pm 2.15$ & - & 0.01 \\
\hline \multirow[t]{3}{*}{ Indirect bilirubin at 24th hour(mg/dl) } & $10.04 \pm 1.11$ & - & $12.04 \pm 2.05$ & 0.000 \\
\hline & - & $8.82 \pm 1.11$ & $12.04 \pm 2.05$ & 0.000 \\
\hline & $10.04 \pm 1.11$ & $8.82 \pm 1.11$ & - & 0.001 \\
\hline \multirow[t]{3}{*}{ Indirect bilirubin at 48th hour(mg/dl) } & $7.96 \pm 1.75$ & - & $10.17 \pm 1.96$ & 0.000 \\
\hline & - & $6.21 \pm 1.06$ & $10.17 \pm 1.96$ & 0.000 \\
\hline & $7.96 \pm 1.75$ & $6.21 \pm 1.06$ & - & 0.000 \\
\hline \multirow[t]{3}{*}{ Indirect bilirubin at discharge $(\mathrm{mg} / \mathrm{dl})$} & $4.75 \pm 1.07$ & - & $7.88 \pm 2.11$ & 0.000 \\
\hline & - & $4.74 \pm 0.63$ & $7.88 \pm 2.11$ & 0.000 \\
\hline & $4.75 \pm 1.07$ & $4.74 \pm 0.63$ & - & 0.97 \\
\hline
\end{tabular}


Table IV. Hospital stay duration and type of nutrition in three groups.

\begin{tabular}{|c|c|c|c|c|c|c|c|c|}
\hline & \multirow{2}{*}{ Variable } & \multicolumn{2}{|c|}{ Control } & \multicolumn{2}{|c|}{$5 \mathrm{mg}$ group } & \multicolumn{2}{|c|}{$7.5 \mathrm{mg}$ group } & \multirow{2}{*}{ pvalue } \\
\hline & & Frequency & percent & Frequency & percent & Frequency & percent & \\
\hline \multirow{4}{*}{$\begin{array}{l}\text { Neonatal } \\
\text { duration of } \\
\text { hospital stay }\end{array}$} & $<1$ day & 7 & 17.5 & 17 & 42.5 & 29 & 72.5 & \multirow[t]{4}{*}{0.000} \\
\hline & 2 day & 10 & 25 & 20 & 50 & 10 & 25 & \\
\hline & 3 day & 21 & 52.5 & 1 & 2.5 & 1 & 2.5 & \\
\hline & $>3$ day & 2 & 5 & 2 & 5 & 0 & 0 & \\
\hline \multirow[t]{3}{*}{ Type of feeding } & Breast milk & 28 & 70 & 34 & 85 & 30 & 75 & \multirow[t]{3}{*}{0.43} \\
\hline & $\begin{array}{c}\text { Breast milk + } \\
\text { formula }\end{array}$ & 9 & 22.5 & 3 & 7.5 & 6 & 15 & \\
\hline & Formula only & 3 & 7.5 & 3 & 7.5 & 4 & 10 & \\
\hline
\end{tabular}

$14.4,12.5$, and $10.1 \mathrm{mg} / \mathrm{dl}$ in the control group, respectively $(p=0 / 05)$. Hassan et al. ${ }^{16}$ reported in their study that the mean indirect bilirubin levels of the infants 12, 24, and 36 hours after hospitalization were $11.7,8.8$, and $7.6 \mathrm{mg} / \mathrm{dl}$ in the UDCA group and 14.6, 13.2, and 10.2 $\mathrm{mg} / \mathrm{dl}$ in the control group, respectively. They observed that the reduction of bilirubin levels in the patients receiving UDCA was significantly higher than that of the patients in the control group $(p=0.00)$. In Jafari et al.' $\mathrm{s}^{17}$ study, the mean indirect bilirubin level in the infants was measured. They illustrated that the reduction of bilirubin levels in the UDCA -receiving groups was significantly higher when compared to the control group. They also reported that the most effective dose of this medication for bilirubin reduction is $10 \mathrm{mg} / \mathrm{kg} /$ day. In another study, conducted by George et al. ${ }^{18}$ the administration of UDCA reduced serum bilirubin level in 4 of the five infants suffering from cholestasis.

On the other hand, Maldonado et al. ${ }^{19}$ investigated neonatal icterus in their study and found that UDCA is more effective than phenobarbital in reducing bilirubin levels. However, in Rina et al. $^{20}$ study, the use of UDCA failed to bring about significant changes in hepatic parameters over seven days. In their study, the reduction of total bilirubin level was reported to be $2.2 \mathrm{mg} / \mathrm{dl}$ in the patients receiving UDCA and $1.7 \mathrm{mg} / \mathrm{dl}$ in the patients of the control group $(p=0.80)$. Altogether, a review of the previous studies showed that the use of UDCA has led to a decrease in the infants bilirubin level. It should be noted that this medication has been administered along with phototherapy and the additional administration of UDCA has enhanced the therapeutic effects of phototherapy. Therefore, the findings of the present study are consistent with those of other studies.

In the study by Honar et al. ${ }^{11}$, the average length of hospital stay was reported to be 15.5 hours for the group of patients receiving UDCA and 44.6 hours for those in the control group. They found that there was a significant association between the duration of stay in the hospital and the administration of UDCA $(p=0.00)$. In another study, Hassan et al. ${ }^{16}$ reported the average length of stay in the hospital to be 23.2 hours for the neonates receiving UDCA and 41.1 hours for those in the control group ( $\mathrm{p}=$ $0.00)$. Jafari et al. ${ }^{17}$ also reported similar findings. However, in Lewis et al. ${ }^{22}$ study, the length of hospital stay for the infants receiving UDCA was found to be similar to that of the infants receiving phenobarbital. In other words, in their study, the administration of Ursobil failed to depict significant changes in the infants length of stay in the hospital $(p=0.45)$. The findings of the present study are similar to Honar' $\mathrm{s}^{11}$ and Hassan' ${ }^{16}$ studies. In our study, as in other studies, the administration of UDCA in patients led to a significant decrease in hospital stay and phototherapy duration. However, although the findings of our study and many other studies indicated the effectiveness of administering UDCA along with phototherapy, further studies with a larger sample size are required before routine administration of UDCA for neonatal 
hyperbilirubinemia. The strengths of this study were the assessment of two different doses of UDCA and the investigation of a large number of patients. Its limitations, on the other hand, were the lack of long-term follow-up and the absence of multicenter trials. It is recommended future studies with a large number of patients, long term follow up of patients and also in neonates with severe hyperbilirubinemia near the exchange transfusion threshold before routine use of UDCA.

The findings of this study indicated that the administration of UDCA in addition to phototherapy, on infants suffering from neonatal jaundice might lead to the shorter length of hospital stay and rapid decrease in the unconjugated bilirubin concentrations and limited brain exposure to its neurotoxic effects.

\section{Acknowledgments}

The researchers express their deepest gratitude to all the parents and the staff of the neonatal department of the hospital for their cooperation in conducting this research.

\section{REFERENCES}

1. Stevenson DK, Fanaroff AA, Maisels MJ, et al. Prediction of hyperbilirubinemia in near-term and term infants. Pediatrics 2001; 108: 31-39.

2. Faulhaber FRS, Procianoy RS, Silveira RC. Side effects of phototherapy on neonates. Am J Perinatol 2019; 36: 252-257.

3. American Academy of Pediatrics Subcommittee on Hyperbilirubinemia. Management of hyperbilirubinemia in the newborn infant 35 or more weeks of gestation. Pediatrics 2004; 114: 297316.

4. Ip S, Chung M, Kulig J, et al; American Academy of Pediatrics Subcommittee on Hyperbilirubinemia. An evidence-based review of important issues concerning neonatal hyperbilirubinemia. Pediatrics 2004; 114: e130-e153.

5. Moslehi MA, Pishva N. Determination of the effect of low dose vs moderate dose clofibrate on decreasing serum bilirubin in healthy term neonates. Iran J Ped 2007; 17: 108-112.
6. Pashapour N, Maccoei A, IOU SG, Akhondi H. The study of a new method in treatment of term newborns with non-hemolytic hyperbilirubinemia. Med J Islamic World Acad Sci 2010; 18: 5-8.

7. Zahedpasha Y, Ahmadpour-Kacho M, Hajiahmadi M, Naderi S. Effect of clofibrate in jaundiced fullterm infants: a randomized clinical trial. Arch Iran Med 2007; 10: 349-353.

8. Dennery PA. Pharmacological interventions for the treatment of neonatal jaundice. Semin Neonatol 2002; 7: 111-119.

9. Cuperus FJ, Hafkamp AM, Havinga R, et al. Effective treatment of unconjugated hyperbilirubinemia with oral bile salts in Gunn rats. Gastroenterology 2009: 136: 673-682.e1.

10. Gludd C, Christensen E. Ursodeoxycholic acid for primary biliary cirrhosis. Cochrane Database Syst Rev 2002; 1: CD00051.

11. Honar N, Ghashghaei Saadi E, Saki F, Pishva N, Shakibazad N, Hosseini Teshnizi S. Effect of ursodeoxycholic acid on indirect hyperbilirubinemia in neonates treated with phototherapy. J Pediatr Gastroenterol Nutr 2016; 62: 97-100.

12. Sokol RJ, Durie PR. Recommendation for management of liver and biliary tract disease in cystic fibrosis. Cystic fibrosis foundation hepatobiliary disease consensus group. J Pediatr Gastroenterol Nutr 1999; 28(Suppl 1): s1-s13.

13. Beuers F, Lindor KD. A major step towards effective treatment evaluation in primary biliary cirrhosis. J Hepatol 2011; 55: 1178-1180.

14. Mendes F, Lindor KD. Primary sclerosing cholangitis: overview and update. Nat Rev Gastroenterol Hepatol 2010; 7: 611-619.

15. Balistreri WF. Bile acid therapy in pediatric hepatobiliary disease: the role of ursodeoxycholic acid. J Pediatr Gastroenterol Nutr 1997; 24: 573-589.

16. Hassan MA, Abdulrahman A, Hasan Husain R. Effect of ursodeoxycholic acid in lowering neonatal indirect hyperbilirubinemia: a randomized controlled trial. Merit Res J Med Med Sci 2015; 3: 402-405.

17. Jafari SH, Khan KA, Bhatnagar SH, Srivastava G, Nanda C, Chandra A. Role of ursodeoxycholic acid in neonates with indirect hyperbilirubinemia-an open labeled randomized control trial. Int J Contemp Pediatr 2018; 5: 432-435.

18. George R, Stevens A, Berkenbosch JW, Turpin J, Tobias J. Ursodeoxycholic acid in the treatment of cholestasis and hyperbilirubinemia in pediatric intensive care unit patients. South Med J 2002; 95: 1276-1279. 
19. Maldonado SR, Godínez Téllez NC, Yescas-Buendía G, Fernán-Carrocera LA, Echaniz- Avilés OL, Reyna Ríos ER. Effectiveness of ursodeoxycholic acid vs. phenobarbital for the treatment of neonatal cholestasis: a cross-randomized clinical trial. Bol Med Hosp Infant Mex 2010; 67: 418-424.

20. Rina RM, Oswari H, Amalia P. Ursodeoxycholic acid in neonatal sepsis-associated cholestasis. Paediatr Indones 2014; 54: 206-212.
21. Bowlus CL, Kenney JT, Rice G, Navarro R. Primary biliary cholangitis: medical and specialty pharmacy management update. J Manag Care Spec Pharm 2016; 22(10-a-s Suppl): S3-S15.

22. Lewis T, Kuye S, Sherman A. Ursodeoxycholic acid versus phenobarbital for cholestasis in the Neonatal Intensive Care Unit. BMC Pediatr 2018; 18: 197. 